\title{
Perioperative Complications and Safety Evaluation of Robot-Assisted Radical Hysterectomy of Cervical Cancer After Neoadjuvant Chemotherapy
}

This article was published in the following Dove Press journal: Cancer Management and Research

\author{
Wei-Fu Chang ${ }^{1-3}$ \\ Ai-Jing Luo 1,3,4 \\ Yi-Feng Yuan ${ }^{5}$ \\ Yang Chen ${ }^{5}$ \\ Zi-Rui Xin ${ }^{3,5}$ \\ Shuai-Shuai $\mathrm{Xu}{ }^{\prime}$ \\ 'Xiangya School of Public Health, Central \\ South University, Changsha 410008, \\ Hunan, People's Republic of China; ${ }^{2}$ The \\ Third Xiangya Hospital of Central South \\ University, Changsha 410013, Hunan, \\ People's Republic of China; ${ }^{3}$ Key \\ Laboratory of Medical Information \\ Research, Central South University, \\ Changsha 410013, Hunan, People's \\ Republic of China; ${ }^{4}$ The Second Xiangya \\ Hospital of Central South University, \\ Changsha 4I00II, Hunan, People's \\ Republic of China; ${ }^{5}$ School of Life \\ Sciences, Central South University, \\ Changsha 4I0013, Hunan, People's \\ Republic of China
}

Correspondence: Ai-jing Luo

The Second Xiangya Hospital of Central South University, 139 Renmin Middle

Road, Furong District, Changsha 4I00II,

Hunan, People's Republic of China

Email574224075@qq.com
Purpose: To evaluate the perioperative complications of patients with cervical cancer who are treated with robot-assisted radical hysterectomy (RRH) and to further evaluate the safety of patients undergoing NACT.

Methods: A total of 805 consecutive cervical cancer patients undergoing RRH were involved in this report. Their clinical characteristics were retrieved from hospital medical records. Perioperative complications were subdivided into intraoperative and postoperative complications, which were graded according to the Clavien-Dindo classification (CDC), and the complications of grade III and above were defined as severe complications. Furthermore, the twolevel logistic regression model was used to estimate the risk factors of perioperative and severe complications and to further confirm the relationship between NACT and perioperative and severe complications.

Results: The perioperative complication rate and severe complications were $45.09 \%$ and $7.83 \%$, respectively. Poorly differentiated tumor and NACT were identified as independent risk factors for perioperative complications by multifactor analysis. Furthermore, we concentrated on the relations between NACT and complications. The risk of perioperative complications of the group with NACT $(\mathrm{OR}=11.08,95 \% \mathrm{CI}$ : 5.70-21.54) was significantly higher than the group without NACT, especially in postoperative complications ( $\mathrm{OR}=17.65$, 95\% CI: 8.63-36.08), even after adjusting confounding factors. However, there was no statistically significant difference in terms of severe complications ( $\mathrm{OR}=1.68,95 \% \mathrm{CI}$ : $0.64-4.41)$ and intraoperative complications ( $\mathrm{OR}=0.51,95 \% \mathrm{CI}$ : $0.18-1.41)$. Moreover, as the times of NACT increase, the impact on perioperative complications is more pronounced. A similar trend was observed in postoperative complications, while this statistical difference was still not observed in intraoperative and severe complications.

Conclusion: This result demonstrates the feasibility and safety of RRH of cervical carcinoma after NACT in generally, since it only causes mild complications, not severe complications.

Keywords: cervical carcinoma, robot-assisted radical hysterectomy, neoadjuvant chemotherapy, Clavien-Dindo classification, perioperative complications

\section{Introduction}

Despite advances in prevention, screening, diagnosis, and treatment during the past decade, cervical cancer remains a major issue of public health, representing the fourth most common female malignancy worldwide. ${ }^{1}$ Approximately $90 \%$ of the 270000 cervical cancer deaths in 2015 occurred in low income and middle-income countries. ${ }^{2}$ An increasing trend in incidence and mortality of cervical cancer has also been observed in China. ${ }^{3}$ 
With advances in the development of instrumentation and surgical expertise, we witnessed a progressive shift from traditional open surgery towards minimally invasive surgery in the treatment of cervical cancer. Minimally invasive surgery is now considered as a widely accepted approach for the management of early-stage gynecological malignancies, which is particularly beneficial in terms of blood loss, pain, hospitalization and recovery, without detrimental effects on the curative or survival outcomes. ${ }^{4-6}$

Robotic surgery is the most advanced technology for minimally invasive surgery, which was approved by the US Food and Drug Administration for gynecology in 2005. Sert et al. were the first to report robot-assisted radical hysterectomy (RRH) and lymph node dissection in 2006. ${ }^{7,8}$ In 2015, our hospital carried out the first RRH operation. In order to ensure better surgical quality and standardization of the entire procedure from preoperation to post-operation, in this study, a total of 805 cervical cancer patients received RRH. However, this treatment method is somewhat controversial. Several studies revealed that minimally invasive surgery may be associated with shorter overall survival than open surgery ${ }^{9}$ and increased rates of death and recurrence ${ }^{10}$ in patients with cervical cancer. This may lead to a paradigm shift in the treatment of cervical cancer, therefore we further evaluate the data from our institution.

In previous studies, a great deal of articles focused on the long-term effects after $\mathrm{RRH},{ }^{9-13}$ while researches on the short-term effects were rare relatively. In order to better evaluate this therapeutic approach, we concentrated on the short-term perioperative impacts of RRH on patients. Although there were a little of researches about perioperative complications for cervical carcinoma, ${ }^{14,15}$ most studies were based on retrospective reviews of medical records or were performed without consideration of the severity of each complication or based on their own criteria. Therefore, it is probable that not all complications have been fully documented, and it is difficult to compare complication rates and identify risk factors for complications reliably.

The incidence of perioperative complication is an important index reflecting the effect of surgery, and the principle of classification for perioperative complications should be simple, reproducible, flexible, and applicable irrespective of the cultural background. ${ }^{16,17}$ Such requirements are met by the Clavien-Dindo classification (CDC) proposed in $2004 .^{18}$ Since then, this classification has been applied to many surgeries including gastrectomy, renal cell cancer resection, colorectal resection, pancreaticoduodenectomy, breast cancer and urological resection. ${ }^{17,19-22}$ However, the perioperative complications assessed by $\mathrm{CDC}$ in radical hysterectomy of cervical cancer have been described scarcely.

Therefore, the purpose of this study is to analyze the severity of perioperative complications of cervical cancer patients undergoing RRH by CDC, evaluate the relationship between NACT and complications, and further confirm the feasibility and safety of RRH of cervical carcinoma after NACT.

\section{Materials and Methods \\ Patients}

From January 2016 to April 2019, a total of 805 patients receiving RRH in our hospital were asked to participate in this retrospective observational study. 244 patients underwent NACT, and 561 patients did not receive NACT. After patients received NACT treatment for 3 courses, the eligible patients wanted to receive RRH with Da Vinci Si Surgical System. The surgery was performed by an experienced surgical team proficient in gynecologic oncology, the member of which all have extensive experience in minimally invasive surgery. All pathological diagnosis was confirmed by two experienced pathologists.

The study was approved by the institutional review board (IRB) of the Third Xiangya Hospital, Central South University. Radical hysterectomy was performed for all patients with proper consultation and written informed consent was obtained from each subject.

\section{Data Collection}

Data of patients' demographics, laboratory examination, clinical manifestation and perioperative complications were obtained from medical records, which include age, stage according to the International Federation of Gynecology and Obstetrics (FIGO), histopathological type, tumor grade, American Association of Anesthesiologists (ASA) classification, classification for HPV and NACT. Intraoperative parameters include mean surgical time, blood loss, number and metastasis condition of pelvic lymph nodes and postoperative hospital stay. According to the definition of perioperation, perioperative complications are divided into intraoperative complications and postoperative complications.

\section{NACT Regimen}

Patients with squamous cell carcinoma received 3 courses of TIP (paclitaxel $175 \mathrm{mg} / \mathrm{m}^{2}+$ ifosfamide $5 \mathrm{~g} / \mathrm{m}^{2}+$ cisplatin 
$75 \mathrm{mg} / \mathrm{m}^{2}$ ), and patients with cervical adenocarcinoma received 3 courses of TEP (paclitaxel $175 \mathrm{mg} / \mathrm{m}^{2}+$ epirubicin $80 \mathrm{mg} / \mathrm{m}^{2}+$ cisplatin $\left.75 \mathrm{mg} / \mathrm{m}^{2}\right)^{23-25}$ The rest of the chemotherapy regimens were performed with reference to the clinician's experience and the actual situation of the patients. Within 2-3 weeks after the completion of NACT, patients were re-evaluated through imaging and physical examination. After the assessment was passed, Da Vinci robot-assisted hysterectomy was performed for the patient with the patient's knowledge and consent.

\section{Perioperative Complications}

Perioperative complications were defined according to previously reported references, and subdivided into intraoperative and postoperative complications. ${ }^{18,26}$ Intraoperative complications included transfusion within $72 \mathrm{~h}$ after surgery, ureter or bladder injury and bowel injury. Postoperative complications included fever $\left(>38^{\circ}\right.$ C) for $>24 \mathrm{~h}$ postoperatively, urinary retention, short-term abnormal liver and renal function, severe edema of lower extremity, lymphocytic cyst infection, postoperative infection, severe anemia, bowel obstruction, vaginal vault dehiscence, vault bleeding, urinary tract infection, lymphedema, fistula, pelvic infection, remnant drain catheter and deep venous thrombosis. All perioperative complications were classified into 5 grades according to CDC. Grade I complications: no special treatment is required; Grade II complications: medical treatment and parenteral nutrition are required; Grade III complications: surgery, endoscopic or radiological intervention are required to be performed under general anesthesia (Class IIIb) or local anesthesia (Class IIIa); Grade IV complications: intensive care is required due to single or multiple organ failure; Grade V complications: death. ${ }^{17}$

\section{Statistical Analysis}

Statistical analyses were performed using IBM SPSS Statistics23.0 (IBM SPSS Inc., Chicago, IL). Descriptive statistics were performed on the distributions of demographic characteristics and perioperative complications. Continuous data were described as mean \pm standard deviation and categorical data as number (percentage). Continuous variables were compared using the Student $T$-test or Mann-Whitney $U$-test. Categorical variables were compared using the Chi-square test or Fisher's exact test. Two-level logistic regression model was used to evaluate the risk factors between NACT and perioperative and severe complications. Two-level logistic regression model was used to estimate the odds ratio (OR) and the 95\% confidence interval (CI) of the risk of perioperative complications by analysis of multiple clinical indicators. Variables with $p<0.05$ in the univariate analysis were considered in a multivariate analysis. $P<0.05$ was considered statistically significant.

\section{Results}

\section{Patient Characteristics}

The demographic characteristics of the study population are shown in Table 1. 805 patients receiving RRH were included in the study, among which, 244 patients $(30.31 \%)$ underwent NACT and 561 patients (69.69\%) did not receive NACT. 439 patients $(54.53 \%)$ were in stage IAIB and 366 patients (45.47\%) were in stage II or above by FIGO staging. Medium differentiation of tumor grade and squamous of histology cell were observed at highest frequency in $489(60.75 \%)$ and 641 (79.63\%), respectively. 164 patients $(20.37 \%)$ had preoperative comorbidities with ASA score $\geq 3$. Type 16 and 18 of HPV were regarded as relatively high risk for cervical carcinoma and were detected in 587 patients $(79.92 \%) .137$ patients $(17.02 \%)$ showed lymph node metastasis. The median of surgical time, blood loss, indwelling time of drainage tube and postoperative hospital stay were 140.00, 150.00 and 3.00, respectively. The mean of age, number of pelvic lymph nodes and days of postoperative hospital stay were 49.44, 12.74 and 7.40 , respectively.

\section{Perioperative Complications}

Detailed information on perioperative complications in patients are shown in Table 2. In this study, of 805 patients receiving RRH, 363 patients $(45.09 \%)$ had perioperative complications; 64 patients $(7.95 \%)$ had intraoperative complications; 328 patients $(40.75 \%)$ had postoperative complications; and 29 patients had both intraoperative and postoperative complications. According to the CDC, 334 (60.95\%), 146 (26.64\%), 66 (12.04\%), 2 (0.36\%) and 0 $(0.00 \%)$ perioperative complications were classified as Grade I, Grade II, Grade III, Grade IV and Grade V, respectively. Severe complications are defined Grade III and above according to CDC. Our study showed that most of the complications of patients receiving RRH were grades I and II, and the most common complications were Grade I urinary retention and Grade II urinary tract infection, however there were also 63 cases of severe complications. 
Table I Summary of Patient Characteristics

\begin{tabular}{|c|c|}
\hline Characteristics & Total $(n=805)$ \\
\hline Age (years) & $49.44 \pm 9.19$ \\
\hline \multicolumn{2}{|l|}{ Stage (FIGO) } \\
\hline$|A|$ & $189(23.49 \%)$ \\
\hline IA2 & $8(0.99 \%)$ \\
\hline$|B|$ & $215(26.71 \%)$ \\
\hline IB2 & 27 (3.35\%) \\
\hline IIAI & 150 (I8.63\%) \\
\hline IIA2 & 87 (10.8I\%) \\
\hline IIB and above & $129(16.02 \%)$ \\
\hline \multicolumn{2}{|l|}{ Tumor grade } \\
\hline Well differentiated & 99 (12.30\%) \\
\hline Moderately differentiated & 489 (60.75\%) \\
\hline Poorly differentiated & $217(26.96 \%)$ \\
\hline \multicolumn{2}{|l|}{ Histopathological type } \\
\hline Adenosquamous carcinoma & $18(2.24 \%)$ \\
\hline Squamous & $64 \mid(79.63 \%)$ \\
\hline Adenocarcinoma & 76 (9.44\%) \\
\hline Other & 70 (8.70\%) \\
\hline \multicolumn{2}{|l|}{ ASA classification } \\
\hline I & 38 (4.72\%) \\
\hline II & 603 (74.91\%) \\
\hline$\geq$ & $164(20.37 \%)$ \\
\hline \multicolumn{2}{|l|}{ Classification for HPV } \\
\hline Negative & $42(5.22 \%)$ \\
\hline Low risk & $7(0.87 \%)$ \\
\hline High risk & 169 (20.99\%) \\
\hline Extremely high risk & 587 (72.92\%) \\
\hline \multicolumn{2}{|l|}{ Lymph node metastasis } \\
\hline No & $668(82.98 \%)$ \\
\hline Yes & 137 (I7.02\%) \\
\hline \multicolumn{2}{|l|}{ Neoadjuvant chemotherapy } \\
\hline No & $561(69.69 \%)$ \\
\hline Yes & $244(30.31 \%)$ \\
\hline Surgical time (mins) & $140.00(115.00-169.75)$ \\
\hline Blood loss (mL) & $150.00(80.00-250.00)$ \\
\hline Number of lymph nodes dissection & $12.74 \pm 8.16$ \\
\hline Indwelling time of drainage tube (day) & $3.00(2.00-3.00)$ \\
\hline Postoperative hospital stay(day) & $7.40 \pm 2.34$ \\
\hline
\end{tabular}

Abbreviations: FIGO, International Federation of Gynecology and Obstetrics; ASA, American Society of Anesthesiologists; HPV, human papillomavirus.

\section{Risk Factors for Perioperative and Severe Complications}

The univariate analysis showed that perioperative complications correlated significantly with age $(p=0.008)$, clinical staging by FIGO $(p<0.001)$, tumor grade $(p<0.001)$, histopathological type $(p<0.001)$, lymph node metastasis
Table 2 Perioperative Complications

\begin{tabular}{|l|l|l|}
\hline CDC & Number & $\begin{array}{l}\text { Percent } \\
\text { (\%) }\end{array}$ \\
\hline Perioperative complications & 363 & 45.09 \\
Intraoperative complications & 64 & 7.95 \\
Postoperative complications & 328 & 40.75 \\
Severe complications & 63 & 7.83 \\
CDC classification & 548 & 100.00 \\
\hline Grade I & 334 & 60.95 \\
Fever (>38 ${ }^{\circ}$ C) & 53 & 9.67 \\
Urinary retention & 141 & 25.73 \\
Short-term abnormal liver function & 51 & 9.31 \\
Short-term abnormal renal function & 9 & 1.64 \\
Severe edema of lower extremity & 4 & 0.73 \\
Lymphocytic cyst & 26 & 4.74 \\
Intraoperative blood transfusion & 50 & 9.12 \\
\hline Grade II & 146 & 26.64 \\
High fever with elevated white blood & 48 & 8.76 \\
cells & & \\
Urinary tract infection & 84 & 15.33 \\
Severe anemia & 2 & 0.36 \\
Lymphocytic cyst infection & 5 & 0.91 \\
Bowel obstruction & 7 & 1.28 \\
\hline Grade & 66 & 12.04 \\
Bowel injury & 6 & 1.09 \\
Bladder or ureter injury & 11 & 2.01 \\
Ureteroscopy & 1 & 0.18 \\
Vaginal vault dehiscence & 6 & 1.09 \\
Vaginal fistula & 36 & 6.57 \\
Bladder vaginal fistula & 4 & 0.73 \\
Lymphatic fistula & 2 & 0.36 \\
\hline Grade IV & 2 & 0.36 \\
Deep vein thrombosis & 0.36 \\
\hline
\end{tabular}

$(p<0.001)$, NACT $(p<0.001)$, surgical time $(p=0.011)$, blood loss $(p<0.001)$, number of pelvic lymph node dissection $(p=0.001)$ and indwelling time of drainage tube $(p<0.001)$ (Table 3). Factors with $p$ value $<0.05$ in the univariate analysis were selected as covariables in the two-level logistic regression analysis. It was found that NACT ( $\mathrm{OR}=9.59,95 \% \mathrm{CI}$ : $6.43-$ $14.28, \mathrm{p}<0.001$ ) was an independent risk factor for a higher perioperative complication rate. Besides, compared with welldifferentiated tumor, moderately differentiated $(\mathrm{OR}=1.85$, 95\% CI: $1.03-3.33, \mathrm{p}=0.041)$ and poorly differentiated tumor $(\mathrm{OR}=4.63,95 \% \mathrm{CI}: 3.08-6.96, \mathrm{p}<0.001)$ (Table 4$)$ are another independent risk factor for a higher perioperative complication rate. For severe complications, the univariate analysis was only significantly correlated with human papillomavirus typing $(P=0.008)$, and no further multivariate analysis was conducted. 
Table 3 Univariate Analysis of Risk Factors for Perioperative and Severe Complications After Robot-Assisted Radical Hysterectomy

\begin{tabular}{|c|c|c|c|c|}
\hline Variables & Perioperative Complications (\%) & $P$-value & Severe Complications (\%) & $P$-value \\
\hline Age(years) & $50.38 \pm 8.90$ & 0.008 & $49.75 \pm 9.85$ & 0.783 \\
\hline $\begin{array}{l}\text { Stage (FIGO) } \\
\text { IAI } \\
\text { IA2 } \\
\text { IBI } \\
\text { IB2 } \\
\text { IIAI } \\
\text { IIA2 } \\
\text { IIB }\end{array}$ & $\begin{array}{l}17.36(63 / 189) \\
0.00(0 / 8) \\
32.09(69 / 215) \\
48.15(13 / 27) \\
38.67(58 / 150) \\
66.67(58 / 87) \\
79.07(102 / 129)\end{array}$ & $<0.001$ & $\begin{array}{l}7.41(14 / 189) \\
0.00(0 / 8) \\
8.84(19 / 215) \\
7.41(2 / 27) \\
7.33(11 / 150) \\
9.20(8 / 87) \\
6.98(9 / 129)\end{array}$ & 0.971 \\
\hline $\begin{array}{l}\text { Tumor grade } \\
\text { Well differentiated } \\
\text { Moderately differentiated } \\
\text { Poorly differentiated }\end{array}$ & $\begin{array}{l}26.27(28 / 99) \\
56.85(278 / 489) \\
28.28(57 / 217)\end{array}$ & $<0.001$ & $\begin{array}{l}5.05(5 / 99) \\
8.38(41 / 489) \\
7.83(17 / 217)\end{array}$ & 0.530 \\
\hline $\begin{array}{l}\text { Histopathological type } \\
\text { Adenosquamous carcinoma } \\
\text { Squamous } \\
\text { Adenocarcinoma } \\
\text { Other }\end{array}$ & $\begin{array}{l}55.56(10 / 18) \\
47.43(304 / 641) \\
44.74(34 / 76) \\
21.43(15 / 70)\end{array}$ & $<0.001$ & $\begin{array}{l}5.56(1 / 18) \\
8.11(52 / 641) \\
6.58(34 / 76) \\
7.14(5 / 70)\end{array}$ & $0.94 I$ \\
\hline $\begin{array}{l}\text { ASA classification } \\
\text { I } \\
\text { II } \\
\geq\end{array}$ & $\begin{array}{l}39.47(15 / 38) \\
44.61(269 / 603) \\
48.17(79 / 164)\end{array}$ & 0.557 & $\begin{array}{l}0.00(0 / 38) \\
7.96(48 / 603) \\
9.15(15 / 164)\end{array}$ & 0.167 \\
\hline $\begin{array}{l}\text { Classification for HPV } \\
\text { Negative } \\
\text { Low risk } \\
\text { High risk } \\
\text { Extremely high risk }\end{array}$ & $\begin{array}{l}57.14(14 / 42) \\
45.56(4 / 7) \\
45.66(77 / 169) \\
33.33(268 / 587)\end{array}$ & 0.426 & $\begin{array}{l}2.38(1 / 42) \\
42.86(3 / 7) \\
8.88(15 / 169) \\
7.50(44 / 587)\end{array}$ & 0.008 \\
\hline $\begin{array}{l}\text { Lymph node metastasis } \\
\text { No } \\
\text { Yes }\end{array}$ & $\begin{array}{l}42.37(283 / 668) \\
58.39(80 / 137)\end{array}$ & 0.001 & $\begin{array}{l}7.63(51 / 668) \\
8.76(12 / 137)\end{array}$ & 0.655 \\
\hline $\begin{array}{l}\text { Neoadjuvant chemotherapy } \\
\text { No } \\
\text { Yes }\end{array}$ & $\begin{array}{l}30.84(173 / 561) \\
52.34(190 / 244)\end{array}$ & $<0.001$ & $\begin{array}{l}7.49(42 / 561) \\
8.61(21 / 244)\end{array}$ & 0.669 \\
\hline $\begin{array}{l}\text { Surgical time }(\mathrm{min}) \\
\text { Blood loss }(\mathrm{mL}) \\
\text { Number of lymph nodes dissection } \\
\text { Dwelling time of drainage tube (day) } \\
\text { Postoperative hospital stay (day) }\end{array}$ & $\begin{array}{l}143.00(|2| .00-170.00) \\
200.00(100.00-300.00) \\
13.81 \pm 7.66 \\
3.00(3.00-4.00) \\
7.55 \pm 2.16\end{array}$ & $\begin{array}{l}0.011 \\
<0.001 \\
0.001 \\
<0.001 \\
0.095\end{array}$ & $\begin{array}{l}138.00(\mid 15.00-161.00) \\
200.00(100.00-200.00) \\
12.21 \pm 7.36 \\
3.00(2.00-4.00) \\
7.57 \pm 2.51\end{array}$ & $\begin{array}{l}0.717 \\
0.566 \\
0.591 \\
0.490 \\
0.536\end{array}$ \\
\hline
\end{tabular}

Abbreviations: FIGO, International Federation of Gynecology and Obstetrics; ASA, American Society of Anesthesiologists; HPV, Human papillomavirus.

\section{Associations Between NACT and Complications}

Table 5 shows the association between NACT and perioperative and severe complications. The rough estimate demonstrated NACT was associated with perioperative complications, especially postoperative complications, but not with intraoperative or severe complications. After the confounders of model I was adjusted, it was found that NACT was associated with postoperative complications $(\mathrm{OR}=17.19,95 \% \mathrm{CI}: 8.49-34.83, \mathrm{p}<0.001)$ and perioperative complications $(\mathrm{OR}=10.83$, 95\% CI: 5.62-20.86, $\mathrm{p}<0.001)$. Even if all confounders were adjusted in 
Table 4 Multivariate Analysis of Risk Factors for Perioperative Complications After Robot-Assisted Radical Hysterectomy

\begin{tabular}{|l|l|l|l|}
\hline \multirow{2}{*}{ Variables } & \multicolumn{3}{|l|}{ Perioperative Complications } \\
\cline { 2 - 4 } & OR & $\mathbf{9 5 \%} \mathbf{~ C l}$ & P-value \\
\hline Tumor grade & & & \\
Well differentiated & Ref & & \\
Moderately differentiated & 1.85 & $1.03-3.33$ & 0.041 \\
Poorly differentiated & 4.63 & $3.08-6.96$ & $<0.001$ \\
\hline Neoadjuvant chemotherapy & & & \\
No & Ref & & \\
Yes & 9.59 & $6.43-14.28$ & $<0.001$ \\
\hline
\end{tabular}

Abbreviations: OR, odds ratio; $\mathrm{Cl}$, confidence interval.

model II, NACT was still associated with postoperative complications (OR=17.65, 95\% CI: 8.63-36.08, $\mathrm{p}<0.001)$ and perioperative complications $(\mathrm{OR}=11.08,95 \% \mathrm{CI}$ : 5.70-21.54, $\mathrm{p}<0.001)$. However, NACT was not associated with intraoperative complications $\quad(\mathrm{OR}=0.51, \quad 95 \%$ CI:0.18-1.41, $p=0.194)$ and severe complications (OR=1.68, 95\% CI:0.64-4.41, $p=0.294)$, respectively. Therefore, this seems to indicate that NACT in cervical cancer patients can only lead to an increase in mild complications and has certain safety.

\section{Associations Between Times of NACT and Complications}

As shown in the previous results, NACT is associated with perioperative complications. This study is expected to verify whether the incidence of complications increase as the times of NACT increase. Therefore, the two-level logistic regression model was applied to clarify the special correlation, and results are shown in Table 6. A step-wise algorithm was used to select factors associated with NACT considering the multicollinearities. In the crude model, the risk of perioperative complications in the group with 1
NACT (OR $=6.77,95 \%$ CI: 3.80-12.06, P <0.001) and the group with 2 or more NACTs $(\mathrm{OR}=8.54,95 \% \mathrm{CI}$ : $5.70-12.79, \mathrm{P}<0.001$ ) was higher than the group without NACT and the difference was statistically significant $(\mathrm{P}<0.05)$. Similarly, the postoperative complications in the group with 1 NACT $(\mathrm{OR}=7.74,95 \% \mathrm{CI}$ : 4.41-13.59, $\mathrm{p}<0.001)$ and the group with 2 or more NACTs $(\mathrm{OR}=10.97,95 \%$ CI: 7.31-16.48, $\mathrm{p}<0.001)$ was higher than the group without NACT.As previously depicted, no significant correlation was found between intraoperative complications and severe complications and the times of NACT. After all confounding factors were adjusted; the upward trend still existed stably. The risk of perioperative complications in the group with 1 NACT ( $\mathrm{OR}=9.39,95 \%$ CI: 4.61-19.14, $\mathrm{P}<0.001)$ and the group with 2 or more NACTs $(\mathrm{OR}=10.90,95 \%$ CI: $5.12-23.20, \mathrm{P}<0.001)$ was higher than the group without NACT; the risk of postoperative complications in the group with 1 NACT $(\mathrm{OR}=14.33,95 \% \mathrm{CI}: 6.80-30.16, \mathrm{P}<0.001)$ and the group with 2 or more NACTs (OR=21.34, 95\% CI:9.40-48.43, $\mathrm{P}<0.001)$ was higher than the group without NACT. These seemed to herald a dose-determined relationship between perioperative complications and times of NACT.

\section{Discussion}

Perioperative complications of radical hysterectomy of cervical cancer usually lead to longer hospital stays, higher medical cost, and delayed adjuvant therapy. The incidence of perioperative complications is also an important indicator for measuring the operative quality. However, there is still no consensus on the definition and classification of perioperative complications, which makes it difficult to evaluate the surgical procedure. The principles of complications classification should be simple, reproducible, flexible and convenient, and widely applicable. ${ }^{16}$ To meet these requirements, we adopted the well-standardized classification, known as the Clavien-

Table 5 Association of Neoadjuvant Chemotherapy and Perioperative Complications

\begin{tabular}{|c|c|c|c|c|c|c|}
\hline \multirow[t]{2}{*}{ Complications } & \multicolumn{2}{|l|}{ Crude Model } & \multicolumn{2}{|l|}{ Adjusted Model I ${ }^{\mathbf{a}}$} & \multicolumn{2}{|c|}{ Adjusted Model II } \\
\hline & OR (95\% CI) & $P$-value & OR (95\% Cl) & $P$-value & OR (95\% Cl) & $P$-value \\
\hline Severe complications & $1.16(0.67-2.01)$ & 0.587 & $1.64(0.64-4.20)$ & 0.304 & $\mathrm{I} .68(0.64-4.4 \mathrm{I})$ & 0.294 \\
\hline Intraoperative complications & $0.82(0.46-1.46)$ & 0.819 & $0.49(0.18-1.35)$ & 0.165 & $0.5 I(0 . \mid 8-I .4 I)$ & 0.194 \\
\hline Postoperative complications & $9.77(6.87-13.90)$ & $<0.001$ & $17.19(8.49-34.83)$ & $<0.001$ & $17.65(8.63-36.08)$ & $<0.001$ \\
\hline Perioperative complications & $7.89(5.55-|| .2 \mid)$ & $<0.001$ & $10.83(5.62-20.86)$ & $<0.001$ & II.08 (5.70-2।.54) & $<0.001$ \\
\hline
\end{tabular}

Notes: ${ }^{2}$ Adjust I: Estimates derived from two-level logistic regression models after adjusted for age, tumor grade, histopathological type, clinical FIGO stage, lymph node metastasis; ' Adjust II: Estimates derived from two-level logistic regression models after adjusted for not only the above variations but also for surgical time, blood loss, number of pelvic lymph node dissection and dwelling time of drainage tube.

Abbreviations: $\mathrm{OR}$, odds ratio; $\mathrm{Cl}$, confidence interval. 
Table 6 Association Between Times of Neoadjuvant Chemotherapy with Complications

\begin{tabular}{|c|c|c|c|c|c|c|}
\hline \multirow[t]{2}{*}{ Times of NACT } & \multicolumn{2}{|l|}{ Crude Model } & \multicolumn{2}{|c|}{ Adjusted Model I ${ }^{\mathbf{b}}$} & \multicolumn{2}{|c|}{ Adjusted Model II c } \\
\hline & OR (95Cl) & P-value & OR (95Cl) & P-value & OR (95Cl) & P-value \\
\hline $\begin{array}{l}\text { Severe complications } \\
\text { NA a } \\
\text { One } \\
\text { Two or above }\end{array}$ & $\begin{array}{l}\text { Ref } \\
1.23(0.50-3.00) \\
1.26(0.69-2.30)\end{array}$ & $\begin{array}{l}0.657 \\
0.457\end{array}$ & $\begin{array}{l}\text { Ref } \\
1.67(0.59-4.76) \\
2.49(0.79-7.78)\end{array}$ & $\begin{array}{l}0.334 \\
0.118\end{array}$ & $\begin{array}{l}\text { Ref } \\
\text { I.64 (0.57-4.72) } \\
2.50(0.78-8.00)\end{array}$ & $\begin{array}{l}0.357 \\
0.122\end{array}$ \\
\hline $\begin{array}{l}\text { Intraoperative complications } \\
\qquad A^{\text {a }} \\
\text { One } \\
\text { Two or above }\end{array}$ & $\begin{array}{l}\text { Ref } \\
0.70(0.24-2.00) \\
0.96(0.51-1.79)\end{array}$ & $\begin{array}{l}0.504 \\
0.897\end{array}$ & $\begin{array}{l}\text { Ref } \\
0.54(0.16-1.85) \\
0.60(0.20-1.86)\end{array}$ & $\begin{array}{l}0.324 \\
0.380\end{array}$ & $\begin{array}{l}\text { Ref } \\
0.55(0.16-1.89) \\
0.64(0.21-1.98)\end{array}$ & $\begin{array}{l}0.341 \\
0.443\end{array}$ \\
\hline $\begin{array}{l}\text { Postoperative complications } \\
\text { NA a } \\
\text { One } \\
\text { Two or above }\end{array}$ & $\begin{array}{l}\text { Ref } \\
7.74(4.4|-| 3.59) \\
10.97(7.3 \mid-16.48)\end{array}$ & $\begin{array}{l}<0.001 \\
<0.001\end{array}$ & $\begin{array}{l}\text { Ref } \\
13.95(6.66-29.23) \\
21.91(9.70-49.49)\end{array}$ & $\begin{array}{l}<0.001 \\
<0.001\end{array}$ & $\begin{array}{l}\text { Ref } \\
14.33(6.80-30.16) \\
21.34(9.40-48.43)\end{array}$ & $\begin{array}{l}<0.001 \\
<0.001\end{array}$ \\
\hline $\begin{array}{l}\text { Perioperative complications } \\
\text { NA }{ }^{\text {a }} \\
\text { One } \\
\text { Two or above }\end{array}$ & $\begin{array}{l}\text { Ref } \\
6.77(3.80-12.06) \\
8.54(5.70-12.79)\end{array}$ & $\begin{array}{l}<0.001 \\
<0.001\end{array}$ & $\begin{array}{l}\text { Ref } \\
9.20(4.53-18.68) \\
11.39(5.37-24.16)\end{array}$ & $\begin{array}{l}<0.001 \\
<0.001\end{array}$ & $\begin{array}{l}\text { Ref } \\
9.39(4.61-19.14) \\
10.90(5.12-23.20)\end{array}$ & $\begin{array}{l}<0.001 \\
<0.001\end{array}$ \\
\hline
\end{tabular}

Notes: ${ }^{a}$ NA means not adopting neoadjuvant chemotherapy; ${ }^{b}$ Adjust I: Estimates derived from two-level logistic regression models after adjusted forage, tumor grade, histopathological type, clinical FIGO stage and lymph node metastasis; ${ }^{\mathrm{C} A d j u s t ~ I I: ~ E s t i m a t e s ~ d e r i v e d ~ f r o m ~ t w o-l e v e l ~ l o g i s t i c ~ r e g r e s s i o n ~ m o d e l s ~ a f t e r ~ a d j u s t e d ~ f o r ~ n o t ~ o n l y ~ t h e ~}$ above variations but also for surgical time, blood loss, number of pelvic lymph node dissection and dwelling time of drainage tube.

Abbreviations: OR, odds ratio; $\mathrm{Cl}$, confidence interval.

Dindo classification system, which has been proven to be a reliable tool for quality assessment for surgery in many fields. ${ }^{17,19-22}$ The complication is defined as "any deviation from the normal postoperative course" and the severity is classified according to the type of treatment required, such as surgical intervention or pharmacological treatment. We analyzed and classified the perioperative complications of RRH for cervical cancer.

Different clinical trials reported complication rates ranging widely from $4.2 \%$ to $58.6 \%{ }^{13-15,19,27}$ In the present study, the perioperative and severe complication rates were $45.09 \%$ and $7.83 \%$, respectively. However, the complication rates in our previous studies seem to be somewhat higher because most grade I complications, such as asymptomatic fever and transient hepatic and renal function abnormality, were included in the perioperative complications. Meanwhile, the most common complications were Grade I urinary retention and Grade II urinary tract infection, and it is speculated that patients with robot-assisted surgery have a higher incidence of nerve damage. ${ }^{28}$ Therefore, it is recommended that nursing staff should pay more attention to patients after RRH to improve the quality of surgery.

Then, univariate and multivariate analyses were performed in whole patients to investigate risk factors correlating with perioperative and severe complications. Poorly differentiated tumor and NACT were independent risk factors for perioperative complications, while the only classification of HPV was correlated with severe complications by univariate analysis.

Multivariate analysis indicated that a poorly differentiated tumor was identified as an independent risk factor related to perioperative complications. Previous studies have shown the degree of differentiation was associated with a recurrence rate of cervical cancer. Wang et al suggested that moderately and highly differentiated tumor could indicate a high recurrence rate of cervical cancer, ${ }^{29}$ while Gong et al found that low levels of tumor differentiation were one of the independent risk factors for recurrent cervical cancer. ${ }^{30}$ Researches on differentiated tumor levels related to the short-term effect were rare relatively. In the present study, we found that a poorly differentiated tumor was significantly associated with perioperative complications. Patients with poorly differentiated tumor were always in bad nutritional status, with common symptoms such as anemia, weight loss, and hypoproteinemia. Although we adjusted their nutritional status before the operation, it might still influence the vulnerability of surgical stress and the occurrence of perioperative complications. However, the 
association between tumor grade and complications still needs further studies.

NACT was identified as another predictor for perioperative complications in multivariate analysis. NACT was performed in radical surgery for cervical cancer over 20 years. ${ }^{31}$ Although NACT has chemotherapy toxicity such as gastrointestinal reactions and bone marrow inhibitory reactions, ${ }^{32}$ possible advantages include the potential for decreasing tumor size, reducing lymph nodes metastasis and distant metastasis, which may provide a viable alternative to chemoradiotherapy when radiotherapy is unavailable or radiotherapy is unavoidably delayed. ${ }^{33-35}$ Although the safety and effectiveness of NACT in the treatment of cervical cancer were guaranteed in many reports, ${ }^{25,31,33-36}$ the results of retrospective cohort studies, randomized controlled trials, ${ }^{37}$ and meta-analysis ${ }^{38}$ showed that NACT did not improve the survival outcome of patients with cervical cancer. More specifically, patients who received NACT had a higher recurrence rate, longer median duration of $\mathrm{RRH}$, and more median estimated blood loss. ${ }^{35}$ Therefore, from the available studies, there is insufficient evidence to show that radical hysterectomy with or without NACT can improve the survival rate and outcomes of patients with cervical cancer.

In our study, neither univariate nor multivariate analyses revealed any significant advantages of NACT in perioperative complications. In contrast, NACT was associated with postoperative complications, but not with intraoperative or severe complications. As previously reported, advanced cancer, aortic lymphadenectomy, open surgery and malnutrition were associated with a higher risk of complications. ${ }^{9,39-41}$ In our study, NACT resulted in more postoperative complications, the reasons of which remained unclear. The systemic effects of NACT and adverse reactions of chemotherapy reagents may be the reason for the increased postoperative complications.

However, we found that NACT was not associated with intraoperative and severe complications in this study. Intraoperative complications here included transfusion within $72 \mathrm{~h}$ after surgery, bladder or ureter injury and bowel injury. In previous studies, BMI $>30 \mathrm{~kg} / \mathrm{m}^{2}$, previous abdominal surgery, metabolic/endocrine disorders (excluding diabetes), surgical complexity and final diagnosis were significantly associated with intraoperative complications. ${ }^{42,43}$ We speculated that the occurrence of intraoperative complications would be probably induced by insufficient experiences and learning curves of the surgeon or the specific surgical situations, rather than NACT. On the other hand, NACT was not associated with severe complications in this study. In a Phase II clinical trial, the results showed that the cervical cancer tissue of patients undergoing NACT was of high sensitivity, and because of the short course chemotherapy and low degree of reactions, gastrointestinal reactions such as nausea and vomiting and bone marrow suppression reactions such as leukocyte, hemoglobin and platelet reduction could be well tolerated in most of the patients. ${ }^{44}$ Therefore, we speculate that NACT may not cause severe complications, which seems to reveal the feasibility and safety of RRH for cervical carcinoma after NACT in general.

In order to further clarify whether there is a "special" effect between NACT and complications, we further explored the association between the times of NACT and complications. The results showed that the overall situation was very similar to the multivariate analysis, which demonstrated the risk rate of perioperative complications, especially postoperative complications, increased steadily with the increase of NACT. This result is consistent with the prospective clinical research. ${ }^{45}$ For the "special" effect between NACT and complications, we may speculate that, on the one hand, with the increase of times of NACT, the accumulation of chemical toxicity in patients was gradually obvious, thereby indeed increasing the incidence of perioperative complications; on the other hand, the toxic impacts of continuous NACT were not independent. The impact of previous NACT would affect the effect of the next NACT, which could lead to an increased incidence of complications.

The main advantage of this study is the short-term efficacy, and use of the well-standardized CDC for standard and uniform classification of the surgical complications to supplement the short-term effect of cervical cancer after RRH. Meanwhile, the impact of NACT times on perioperative complications was analyzed to fill the gap in the short-term efficacy of NACT performed before RRH of cervical cancer. However, our study has some limitations. These data are limited to patients' condition during the period of hospitalization. Our study does not consider long-term complications, such as malnutrition recurrence and survival outcome, which may influence the patients' quality of life and mortality. Additionally, since this was a retrospective study, recall bias and selection bias are inevitable, and there is no follow-up statistics on the survival rate, such as disease-free survival and overall survival. In the future, large-scale randomized controlled prospective research is needed with multi-center and multi-sector cooperation to achieve more credible results, eliminate bias, and obtain more surgical results. 


\section{Conclusions}

Our study demonstrates that NACT is a special risk factor of perioperative complications for patients with cervical cancer undergoing RRH, which seems to not lead to serious disease burden due to tolerable clinical toxicity, that is, NACT was closely related to mild postoperative complications. Hence, our study demonstrates the feasibility and safety of RRH of cervical carcinoma after NACT. However, the clinical application of NACT should be selected discreetly. In general, these results provide important clues for future research and provide directions for the adjuvant therapy of cervical cancer.

\section{Acknowledgments}

This study was supported by the Key Research and Development Program of Hunan Province (2017SK2011).

\section{Disclosure}

The authors declare no potential conflicts of interest related to this work.

\section{References}

1. Bray F, Ferlay J, Soerjomataram I, et al. Global cancer statistics 2018: GLOBOCAN estimates of incidence and mortality worldwide for 36 cancers in 185 countries. CA Cancer J Clin. 2018;68 (6):394-424. doi: $10.3322 / \mathrm{caac} .21492$

2. Paul AC, Anjua J, Ana O, et al. Cervical cancer. Lancet. 2019;393 (10167):169-182. doi:10.1016/S0140-6736(18)32470-X

3. Chen W, Zheng R, Baade PD, et al. Cancer statistics in China, 2015. CA Cancer J Clin. 2016;66(2):115-132. doi:10.3322/caac.21338

4. Lowe MP, Chamberlain DH, Kamelle SA, et al. A multi-institutional experience with robotic-assisted radical hysterectomy for early stage cervical cancer. Gynecol Oncol. 2009;113(2):191-194. doi:10.1016/j. ygyno.2009.01.018

5. Cantrell LA, Mendivil A, Gehrig PA, et al. Survival outcomes for women undergoing type III robotic radical hysterectomy for cervical cancer: a 3-year experience. Gynecol Oncol. 2010;117(2):260-265. doi:10.1016/j.ygyno.2010.01.012

6. Wallin E, FlöterRådestad A, Falconer H. Introduction of robotassisted radical hysterectomy for early stage cervical cancer: impact on complications, costs and oncologic outcome. Acta Obstet Gynecol Scan. 2017;96(5):536-542. doi:10.1111/aogs.13112

7. Sert B, Abeler V. Robotic radical hysterectomy in early-stage cervical carcinoma patients, comparing results with total laparoscopic radical hysterectomy cases. The future is now? Int J Med Robot. 2007;3 (3):224-228. doi:10.1002/rcs.152

8. Oyama K, Kanno K, Kojima R, et al. Short-term outcomes of robotic-assisted versus conventional laparoscopic radical hysterectomy for early-stage cervical cancer: a single-center study. J Obstet Gynaecol Res. 2019;45(2):405-411. doi:10.1111/jog.13858

9. Melamed A, Margul DJ, Chen L, et al. Survival after minimally invasive radical hysterectomy for early-stage cervical cancer. $N$ Engl $J$ Med. 2018;379(20):1905-1914. doi:10.1056/ NEJMoa1804923

10. Cusimano MC, Baxter NN, Gien LT, et al. Impact of surgical approach on oncologic outcomes in women undergoing radical hysterectomy for cervical cancer. Am J Obstet Gynecol. 2019;221 (6):619.e1-619.e24. doi:10.1016/j.ajog.2019.07.009
11. Gil-Moreno A, Carbonell-Socias M, Salicrú S, et al. Radical hysterectomy: efficacy and safety in the dawn of minimally invasive techniques. J Minim Invasive Gynecol. 2019;26(3):492-500. doi:10.1016/j.jmig.2018.06.007

12. Chao X, Li L, Wu M, et al. Efficacy of different surgical approaches in the clinical and survival outcomes of patients with early-stage cervical cancer: protocol of a Phase III multicentre randomised controlled trial in China. BMJ Open. 2019;9(7):e29055. doi:10.1136/ bmjopen-2019-029055

13. Doo DW, Kirkland CT, Griswold LH, et al. Comparative outcomes between robotic and abdominal radical hysterectomy for IB1 cervical cancer: results from a single high volume institution. Gynecol Oncol. 2019;153(2):242-247. doi:10.1016/j.ygyno.2019.03.001

14. Chen C, Chiu L, Chang C, et al. Comparing robotic surgery with conventional laparoscopy and laparotomy for cervical cancer management. Int $J$ Gynecol Cancer. 2014;24(6):1105-1111. doi:10.1097/IGC.0000000000000160

15. Matsuo K, Mandelbaum RS, Adams CL, et al. Performance and outcome of pelvic exenteration for gynecologic malignancies: a population-based study. Gynecol Oncol. 2019;153(2):368-375. doi:10.1016/j.ygyno.2019.02.002

16. Clavien PA, Barkun J, de Oliveira ML, et al. The Clavien-Dindo classification of surgical complications. Ann Surg. 2009;250 (2):187-196. doi:10.1097/SLA.0b013e3181b13ca2

17. Zhou J, Yu P, Shi Y, et al. Evaluation of Clavien-Dindo classification in patients undergoing total gastrectomy for gastric cancer. Med Oncol. 2015;32(4). doi:10.1007/s12032-015-0573-3

18. Dindo D, Demartines N, Clavien P. Classification of surgical complications: a new proposal with evaluation in a cohort of 6336 patients and results of a survey. Ann Surg. 2004;240(2):205-213. doi:10.1097/01.sla.0000133083.54934.ae

19. Ebbing J, Wiebach T, Kempkensteffen C, et al. Evaluation of perioperative complications in open and laparoscopic surgery for renal cell cancer with tumor thrombus involvement using the Clavien-Dindo classification. Eur J Surg Oncol. 2015;41(7):941-952. doi:10.1016/j. ejso.2015.02.009

20. Mazeh H, Samet Y, Abu-Wasel B, et al. Application of a novel severity grading system for surgical complications after colorectal resection. J Am Coll Surg. 2009;208(3):355-361. doi:10.1016/j. jamcollsurg.2008.12.008

21. Yoon PD, Chalasani V, Woo HH. Use of Clavien-Dindo classification in reporting and grading complications after urological surgical procedures: analysis of 2010 to 2012. J Urol. 2013;190(4):1271-1274. doi:10.1016/j.juro.2013.04.025

22. Panhofer P, Ferenc V, Schutz M, et al. Standardization of morbidity assessment in breast cancer surgery using the Clavien-Dindo classification. Int $J$ Surg. 2014;12(4):334-339. doi:10.1016/j. ijsu.2014.01.012

23. Lissoni A, Gabriele A, Gorga G, et al. Cisplatin-, epirubicin- and paclitaxel-containing chemotherapy in uterine adenocarcinoma. Ann Oncol. 1997;8(10):969-972. doi:10.1023/A:1008221310453

24. Zanetta G, Lissoni A, Pellegrino A, et al. Neoadjuvant chemotherapy with cisplatin, ifosfamide and paclitaxel for locally advanced squamous-cell cervical cancer. Ann Oncol. 1998;9(9):977-980. doi:10.1023/A:1008461408626

25. Vitobello D, Siesto G, Pirovano C, et al. Surgical outcomes of robotic radical hysterectomy after neoadjuvant chemotherapy for locally advanced cervical cancer: comparison with early stage disease. Eur J Surg Oncol. 2013;39(1):87-93. doi:10.1016/j.ejso.2012.10.001

26. Weinberg L, Rao S, Escobar PF. Robotic surgery in gynecology: an updated systematic review. Obstet Gynecol Int. 2011;2011:1-29. doi: $10.1155 / 2011 / 852061$

27. Wang W, Babu SR, Wang L, et al. Use of Clavien-Dindo classification in evaluating complications following pancreaticoduodenectomy in 1056 cases: a retrospective analysis from one single institution. Oncol Lett. 2018;16(2):2023-2029. doi:10.3892/ol.2018.8798 
28. Kruijdenberg CBM, van den Einden LCG, Hendriks JCM, et al. Robot-assisted versus total laparoscopic radical hysterectomy in early cervical cancer, a review. Gynecol Oncol. 2011;120 (3):334-339. doi:10.1016/j.ygyno.2010.12.342

29. Wang $\mathrm{H}$, Zhu L, Lu W, et al. Clinicopathological risk factors for recurrence after neoadjuvant chemotherapy and radical hysterectomy in cervical cancer. World J Surg Oncol. 2013;11(1):301. doi:10.1186/ 1477-7819-11-301

30. Gong L, Zhang J, Yin R, et al. Safety and efficacy of neoadjuvant chemotherapy followed by radical surgery versus radical surgery alone in locally advanced cervical cancer patients. Int $J$ Gynecol Cancer. 2016;26(4):722-728. doi:10.1097/IGC.00000000000000658

31. Vizza E, Corrado G, Mancini E, et al. Laparoscopic versus robotic radical hysterectomy after neoadjuvant chemotherapy in locally advanced cervical cancer: a case control study. Eur J Surg Oncol. 2015;41(1):142-147. doi:10.1016/j.ejso.2013.08.018

32. Lissoni AA, Colombo N, Pellegrino A, et al. A Phase II, randomized trial of neo-adjuvant chemotherapy comparing a three-drug combination of paclitaxel, ifosfamide, and cisplatin (TIP) versus paclitaxel and cisplatin (TP) followed by radical surgery in patients with locally advanced squamous cell cervical carcinoma: the Snap-02 Italian collaborative study. Ann Oncol. 2009;20(4):660-665. doi:10.1093/ annonc/mdn690

33. Singh U, Ahirwar N, Rani AK, et al. The efficacy and safety of neoadjuvant chemotherapy in treatment of locally advanced carcinoma cervix. $J$ Obstet Gynaecol India. 2013;63(4):273-278. doi:10.1007/s13224-012-0342-6

34. Loizzi V, Cormio G, Vicino M, et al. Neoadjuvant chemotherapy: an alternative option of treatment for locally advanced cervical cancer. GynecolObstetInves. 2008;65(2):96-103. doi:10.1159/000108600

35. Li L, Wu M, Ma S, et al. Neoadjuvant chemotherapy followed by radical hysterectomy for stage IB2-to-IIB cervical cancer: a retrospective cohort study. Int $J$ Clin Oncol. 2019;24 (11):1440-1448. doi:10.1007/s10147-019-01510-1

36. Vizza E, Corrado G, Zanagnolo V, et al. Neoadjuvant chemotherapy followed by robotic radical hysterectomy in locally advanced cervical cancer: a multi-institution study. Gynecol Oncol. 2014;133 (2):180-185. doi:10.1016/j.ygyno.2014.02.035
37. Gupta S, Maheshwari A, Parab P, et al. Neoadjuvant chemotherapy followed by radical surgery versus concomitant chemotherapy and radiotherapy in patients with stage IB2, IIA, or IIB squamous cervical cancer: a randomized controlled trial. J Clin Oncol. 2018;36 (16): 1548. doi:10.1200/JCO.2017.75.9985

38. Zhao H, He Y, Yang S, et al. Neoadjuvant chemotherapy with radical surgery vs radical surgery alone for cervical cancer: a systematic review and meta-analysis. Onco Targets Ther. 2019;12:1881-1891. doi:10.2147/OTT.S186451

39. Ferrandina G, Ercoli A, Fagotti A, et al. Completion surgery after concomitant chemoradiation in locally advanced cervical cancer: a comprehensive analysis of pattern of postoperative complications. Ann Surg Oncol. 2014;21(5):1692-1699. doi:10.1245/s10434-013-3471-y

40. Liang C, Liu P, Cui Z, et al. Effect of laparoscopic versus abdominal radical hysterectomy on major surgical complications in women with stage IA-IIB cervical cancer in China, 2004-2015. Gynecol Oncol. 2019. doi:10.1016/j.ygyno.2019.10.032

41. Uppal S, Al-Niaimi A, Rice LW, et al. Preoperative hypoalbuminemia is an independent predictor of poor perioperative outcomes in women undergoing open surgery for gynecologic malignancies. Gynecol Oncol. 2013;131(2):416-422. doi:10.1016/j.ygyno.2013. 08.011

42. Balaya V, Mathevet P, Magaud L, et al. Predictive factors of severe perioperative morbidity of radical hysterectomy with lymphadenectomy in early-stage cervical cancer: a French prospective multicentric cohort of 248 patients. Eur J Surg Oncol. 2019;45(4):650-658. doi:10.1016/j.ejso.2018.10.057

43. Iyer R, Gentry-Maharaj A, Nordin A, et al. Predictors of complications in gynaecological oncological surgery: a prospective multicentre study (UKGOSOC-UK gynaecological oncology surgical outcomes and complications). Br J Cancer. 2015;112(3):475-484. doi:10.1038/bjc.2014.630

44. McCormack M, Kadalayil L, Hackshaw A, et al. A phase II study of weekly neoadjuvant chemotherapy followed by radical chemoradiation for locally advanced cervical cancer. Br J Cancer. 2013;108 (12):2464-2469. doi:10.1038/bjc.2013.230

45. Hansen H, Høgdall C, Engelholm S. Radiation therapy without cisplatin for elderly cervical cancer patients. Int J Radiat Oncol Biol Phys. 2014;90(1):S484-S485. doi:10.1016/j.ijrobp.2014.05.1499

\section{Publish your work in this journal}

Cancer Management and Research is an international, peer-reviewed open access journal focusing on cancer research and the optimal use of preventative and integrated treatment interventions to achieve improved outcomes, enhanced survival and quality of life for the cancer patient.
The manuscript management system is completely online and includes a very quick and fair peer-review system, which is all easy to use. Visit http://www.dovepress.com/testimonials.php to read real quotes from published authors. 